\title{
Hepatocellular Adenomas Associated with Hepatic Granulomas: Experience in Five Cases
}

\author{
Matthanja Bieze ${ }^{a}$ Paulette Bioulac-Sage ${ }^{c, d}$ \\ Joanne Verheij $^{\text {b }}$ Charles Balabaud ${ }^{d}$ Christophe Laurent $^{\mathrm{e}}$ \\ Thomas M. van Gulik ${ }^{a}$ \\ Departments of ${ }^{a}$ Surgery and ${ }^{b}$ Pathology, Academic Medical Center, University \\ of Amsterdam, Amsterdam, The Netherlands; 'Department of Pathology, \\ Hôpital Pellegrin, CHU Bordeaux, ${ }^{\text {} U 1053, ~ I N S E R M ~ U n i v e r s i t e ́ ~ B o r d e a u x ~}$ \\ Segalen, and ${ }^{e}$ Department of Surgery, Hôpital Saint André, CHU Bordeaux, \\ Bordeaux, France
}

\section{Key Words}

Liver - Hepatocellular adenoma - Hepatic granuloma - Benign - Oral contraceptives · Inflammation

\begin{abstract}
We present five cases in whom two rare entities were simultaneously found within the liver, i.e. hepatocellular adenomas (HCAs) and granulomas. Coexistence of both entities confuses diagnosis. Our aim is to disclose the association between HCA and hepatic granulomas. Five patients presented with HCA for which they underwent resection. During laparotomy or at pathological examination, granulomas were found in tumorous and non-tumorous tissue. No specific cause for the granulomas was found. Immunohistochemistry showed overexpression of C-reactive protein and serum amyloid $A$ in $4 / 5$ patients, classifying these lesions as inflammatory HCA. HCA and especially the inflammatory subtype may cause formation of granulomas in (peri-)tumorous tissue as a local response to persistent inflammation and/or the presence of a tumor. Both HCA and hepatic granulomas have also been associated with oral contraceptive use. In conclusion, HCAs associated with hepatic granulomas derive from a local response to (inflammatory) HCA or neoplasm, chronic use of oral contraceptives, or a combination of these factors.
\end{abstract}




\section{Introduction}

The presence of multiple atypical hepatic lesions in combination with hepatocellular adenoma (HCA) confuses diagnosis when found on imaging or at laparotomy. HCA is a benign hepatic lesion occurring predominantly in young and middle-aged women [1]. Large HCA holds a risk of bleeding (30\%) and malignant transformation (4.3\%). Because of these risks, lesions $>5 \mathrm{~cm}$ are generally resected. Molecular histopathological analysis categorizes HCA according to mutations within the lesions, each with a corresponding immunohistochemical phenotype [2].

Hepatic granulomas hold a wide variety of possible causes, although often a precise cause cannot be obtained [3]. Granulomas form in response to chronic exogenous or endogenous antigen presentation and may also form as a local response to specific agents or neoplasm [4]. Common causes of hepatic granulomas include sarcoidosis, tuberculosis, primary biliary cirrhosis, viral or bacterial hepatitis, parasites and drugs.

In this paper we present five cases of HCA in whom granulomas in the tumor and/or surrounding liver parenchyma were found, and in 1 case even diffuse granulomatous hepatitis (GH). Three papers in the English literature and one in the French literature have reported the coexistence of HCA and liver granulomas in the past 30 years [5-7]. Patient characteristics are summarized in table 1 (upper part). Case 3 has been previously published [5]. An overview of previously published cases is shown in the lower part of table 1.

\section{Case 1}

A 36-year-old woman with a history of diabetes mellitus (DM) and 15 years of oral contraceptive (OC) use was referred to the surgical department. She presented with acute upper abdominal pain caused by bleeding of a hepatic lesion $(12.5 \mathrm{~cm})$ during the 19th week of pregnancy, which was treated by selective arterial embolization of the branches of the feeding hepatic arteries in segment 2 and 3 (fig. 1a). One year later, the patient presented with abdominal pain similar to the pain during the previous episode of bleeding, and imaging showed signs of recurrent bleeding (fig. 1b). At laparotomy the liver surface appeared macroscopically inhomogeneous with disseminated pale lesions of approximately $0.5-1.0 \mathrm{~cm}$ with a tendency to confluence (fig. 1c, d). A diffusely metastasized malignancy was suspected, however intraoperative frozen sections of these lesions revealed granulomas. Histopathological examination showed multiple HCAs: hepatocellular proliferation without cytonuclear atypia, but with the presence of thick-walled vessels, areas of necrosis, hemorrhage, and in some vessels embolization material (fig. 1e). These HCAs remained unclassified as liver fatty acid binding protein (LFABP), glutamine synthetase (GS), C-reactive protein (CRP) and serum amyloid A (SAA) did not show any aberrant expression patterns [8]. Throughout the HCA lesions and liver, tissue was disrupted by epithelioid granulomas with a necrotic center containing multinucleated giant cells (fig. 1f). Ziehl-Neelsen, PAS and Grocott staining were negative. At the outpatient clinic no evidence of sarcoidosis, bacterial or fungal infection was found. Three months after surgery, the patient had fully recovered and resumed work.

\section{Case 2}

A 29-year-old woman was referred to the surgical department. Patient history included 10 years of OC use, DM type I with diabetic nephropathy (creatine $147 \mu \mathrm{mol} / \mathrm{l}$; normal $90 \mu \mathrm{mol} / \mathrm{l}$ ), and severe hypertension (up to $220 / 100 \mathrm{~mm} \mathrm{Hg}$ ) which caused encephalopathy (table 1). A contrast-enhanced MRI to evaluate her renal status incidentally showed multiple hepatic lesions $<2 \mathrm{~cm}$, one lesion of $5 \mathrm{~cm}$ in the left liver, and one lesion in segment 6 of $4.2 \mathrm{~cm}$ (fig. 2). Preoperative liver biopsy 
confirmed the diagnosis of HCA and showed hepatic granulomas in the biopsy specimen. The left-lateral segments of the liver were resected and local excision of the lesion in segment 6 was performed. The lesions were consistent with inflammatory HCA, with hemorrhagic changes, sinusoidal dilatation, influx of inflammatory cells and irregular, thick blood vessels. Immunohistochemical staining showed overexpression of CRP and SAA. Beta-catenin, GS and LFABP expression were not aberrant. Within the HCA lesions and at the border of tumorous and non-tumorous tissue, an influx of epithelioid granulomas was found. There were no signs of sarcoidosis or opportunistic infections, and Ziehl-Neelsen and PAS staining were negative. No peri- or postoperative complications occurred and the patient could be discharged on day 7. Six months after surgery the patient was in good condition.

\section{Case 3}

A 52-year-old woman with a history of type II diabetes was referred to the liver surgical department for resection of multiple hepatic lesions, as previously reported [5]. The patient had had three normal pregnancies after which she had taken OC for 18 years. In a period of 6 years, the tumor in segments $6 / 7$ enlarged from $2 \mathrm{~cm}$ to $7 \mathrm{~cm}$. Ultrasound showed 5 additional smaller nodules measuring 2-3 cm: 4 in the right liver and 1 in segment 2 . A right hepatectomy and enucleation of the lesion in segment 2 was performed. All 6 lesions had the same histopathological characteristics consistent with inflammatory HCA. Immunohistochemical staining revealed an overexpression of SAA and CRP, without abnormalities for LFABP, GS and beta-catenin staining. In addition, there were numerous non-necrotizing granulomas inside all tumors which were not present in the non-tumoral liver. The granulomas were composed of lymphocytes, epithelioid cells and multinucleated giant cells, occasionally containing asteroid bodies. There was no argument for opportunistic infections and the following stainings were negative: Ziehl-Neelsen, PAS, Grocott and Warthin-Starry. The non-tumoral liver parenchyma was normal.

\section{Case 4}

This 39-year-old woman was referred for resection of a $7 \mathrm{~cm}$ hepatic lesion in the right liver lobe discovered by hepatic ultrasound that was carried out for evaluation of elevated serum $\gamma \mathrm{GT}$ (360 U/l; normal <40 U/l). Patient history revealed three normal pregnancies, one miscarriage and one abortion, OC use during 23 years, and DM type II. MRI showed a large subcapsular tumor with central necrosis in the right liver, and 2 hemangiomas in the left lobe. A right hemihepatectomy was performed. On histopathological examination a benign hepatocellular proliferation with necrotic and hemorrhagic changes was found, consistent with HCA. Three small nodules were discovered at some distance from the larger tumor, measuring between 1 and $2 \mathrm{~cm}$. All lesions showed typical features of inflammatory HCA by standard microscopy, confirmed by additional immunohistochemistry with overexpression of SAA and CRP, whereas LFABP, GS and beta-catenin were normally expressed. In addition, small epithelioid granulomas were observed within the tumor mixed with inflammatory infiltrates. The non-tumoral liver was mildly steatotic without granulomas.

\section{Case 5}

A 32-year-old man with DM type I was admitted to the liver surgical department after discovery by ultrasound of a $10 \mathrm{~cm}$ lesion in the left liver lobe. Serum alpha-fetoprotein was normal $(<7 \mathrm{U} / \mathrm{l})$ and there were no indications for primary or secondary malignant disease on additional imaging. A left hemihepatectomy was performed. The tumor, bulging from the posterior side of segment 3 of the liver, was well circumscribed and presented with congestive and hemorrhagic areas. In addition to a typical aspect of inflammatory HCA, there were numerous large epithelioid granulomas dispersed inside the tumor and in the immediate peritumoral parenchyma. The non-tumoral liver at distance was normal, except for many glycogenated nuclei. Immunohistochemical staining showed an overexpression of SAA and CRP inside the tumor, confirming inflammatory HCA. Follow-up after resection was uneventful. 


\section{Discussion}

The presented cases share many similarities, and we therefore propose three possible correlations between HCA and the formation of granulomas.

First of all, the chronic inflammatory stress caused by inflammatory HCA might trigger granuloma formation. Inflammatory HCA is more often seen in patients with DM and obesity, and is the most frequent subtype with an incidence of 55-60\% [9]; all our cases had a history of DM with a BMI $\geq 27$. The hepatic lesions of $4 / 5$ patients were histologically confirmed to be typical inflammatory HCA [1]. The chronic irritation and inflammatory stress caused by (inflammatory) HCA may cause activation of a cascade of inflammatory mediators and result in the formation of granulomas. This was also suggested by Martin-Blondel et al. [7] in their case study of GH and HCA. After resection of HCA the stressor theoretically subsides, which will subsequently result in the disappearance of the granulomas. This was reported in the case of Malatjalian and Graham [10] where a liver biopsy of the remnant liver was performed 6.5 years after resection of the HCA, revealing no evidence of granulomas anymore. However, no report was made about imaging findings and the biopsy was a single specimen, limiting the conclusion drawn from this investigation.

Second, a known cause of hepatic granulomas is the presence of a neoplasm, e.g. Hodgkin's disease or hepatocellular carcinoma [11, 12]. Although HCA is a benign lesion, the liver is likely to respond in a same manner to the presence of the abnormal tumoral tissue.

Finally, chronic OC use might also be an underlying etiological factor in both HCA and hepatic granulomas. OCs are listed as one of many drugs known to cause GH [5, 13]. This drug is also associated with growth and development of HCA $[13,14]$. Therefore chronic OC use may be a common etiological factor in the formation of HCA and hepatic granulomas in our female patients. The first case presented with multiple HCAs and diffuse granulomatous infiltration in both the existing HCA and the entire liver. This case was not an inflammatory HCA, but remained unclassified. The extensive GH likely reflects a systemic cause. All previously reported cases in literature (table 1) presented with a history of chronic OC use. Interestingly, in the patient described by Neuberger et al. [15] in whom a GH was diagnosed in association with OC use, the liver biopsy performed 6 months after discontinuation of OC revealed no granulomas, which supports this hypothesis.

In conclusion, little has been reported on hepatic granulomas in association with HCA. We found, along with HCA, granulomas in (peri)tumorous tissue, but also diffusely infiltrated in the entire liver. We propose that the hepatic granulomas in these cases are a response to persistent inflammation caused by (inflammatory) HCA, a local reaction to a neoplasm, chronic use of OCs, or a combination of these factors.

\section{Disclosure Statement}

The authors have no conflicts of interest to declare. No grant or financial support contributed to this paper. 
Table 1. Summary of patient and lesion characteristics

\begin{tabular}{|c|c|c|c|c|c|c|c|c|c|c|}
\hline Reference & $\begin{array}{l}\text { Age, } \\
\text { years }\end{array}$ & Sex & DM & BMI & $\begin{array}{l}\mathrm{OC}, \\
\text { years }\end{array}$ & $\begin{array}{l}\mathrm{HCA} \\
\mathrm{n}\end{array}$ & $\begin{array}{l}\text { HCA } \\
\text { location }\end{array}$ & $\begin{array}{l}\text { HCA } \\
\text { subtype }\end{array}$ & $\begin{array}{l}\text { Location of } \\
\text { hepatic granulomas }\end{array}$ & $\begin{array}{l}\text { Characteristics of } \\
\text { hepatic granulomas }\end{array}$ \\
\hline $\begin{array}{l}\text { This report } \\
\text { (case 1) }\end{array}$ & 36 & $\mathrm{f}$ & II & 27 & 15 & 7 & diffuse & $\begin{array}{l}\text { unclas- } \\
\text { sified }\end{array}$ & diffuse & $\begin{array}{l}\text { epithelioid, necrotizing; } \\
\text { multinucleated giant } \\
\text { cells; diffuse hilar } \\
\text { lymphadenopathy }\end{array}$ \\
\hline $\begin{array}{l}\text { This report } \\
\text { (case 2) }\end{array}$ & 29 & f & I & 31 & 10 & $>10$ & diffuse & IHCA & border T and NT & epithelioid; non-caseating \\
\hline $\begin{array}{l}\text { This report } \\
\text { (case 3)* }\end{array}$ & 52 & $\mathrm{f}$ & II & 27 & 18 & 6 & diffuse & IHCA & $\mathrm{T}$ & $\begin{array}{l}\text { epithelioid; non-caseating; } \\
\text { multinucleated giant cells }\end{array}$ \\
\hline $\begin{array}{l}\text { This report } \\
\text { (case 4) }\end{array}$ & 39 & $\mathrm{f}$ & II & 28 & 23 & 4 & right & IHCA & $\mathrm{T}$ & \\
\hline $\begin{array}{l}\text { This report } \\
\text { (case 5) }\end{array}$ & 32 & $\mathrm{~m}$ & I & & NA & 1 & left & IHCA & border T and NT & epithelioid \\
\hline $\begin{array}{l}\text { Martin-Blondel } \\
\text { et al., } 2010 \text { [7] }\end{array}$ & 39 & $\mathrm{f}$ & & & & & & & diffuse & epithelioid; non-necrotizing \\
\hline $\begin{array}{l}\text { Neuberger et al., } \\
1980 \text { [15] }\end{array}$ & 28 & $\mathrm{f}$ & & & $5 / 9$ & 1 & & & $\mathrm{~T}$ & \\
\hline $\begin{array}{l}\text { Malatjalian and } \\
\text { Graham, } 1982 \text { [10] }\end{array}$ & 31 & $\mathrm{f}$ & & & 7 & 1 & left & & border T and NT & $\begin{array}{l}\text { epithelioid; non-caseating; } \\
\text { multinucleated giant cells }\end{array}$ \\
\hline $\begin{array}{l}\text { Le Bail et al., } \\
1992[5]\end{array}$ & 39 & $\mathrm{f}$ & & & 12 & 1 & IV & & diffuse & \\
\hline $\begin{array}{l}\text { Grazi et al., } \\
2007[6]\end{array}$ & 26 & $\mathrm{f}$ & & & 10 & 2 & III \& IV-V & & diffuse & $\begin{array}{l}\text { multinucleated giant } \\
\text { cells; diffuse hilar } \\
\text { lymphadenopathy }\end{array}$ \\
\hline
\end{tabular}

Patient characteristics include: age; sex; diabetes mellitus (DM type I or II); body mass index (BMI); years of oral contraceptive use (OC). Lesion characteristics include: number and location of HCA within the liver; subtype of HCA - inflammatory (IHCA) and unclassified; location of hepatic granulomas (diffuse throughout the liver and lesion - within the tumor (T) - border area of tumoral (T) to normal (N) parenchyma); characteristics of HG. * Previously reported [5]. 


\begin{tabular}{r|l|l|l}
$\begin{array}{r}\text { Case Reports in } \\
\text { Gastroenterology }\end{array}$ & $\begin{array}{l}\text { Case Rep Gastroenterol 2012;6:677-683 } \\
\text { DOI: 10.1159/000343434 }\end{array}$ & $\begin{array}{l}\text { Published online: } \\
\text { October 30, 2012 }\end{array}$ & $\begin{array}{l}\text { @ 2012 S. Karger AG, Basel } \\
\text { ISSN 1662-0631 } \\
\text { www.karger.com/crg }\end{array}$ \\
\hline
\end{tabular}
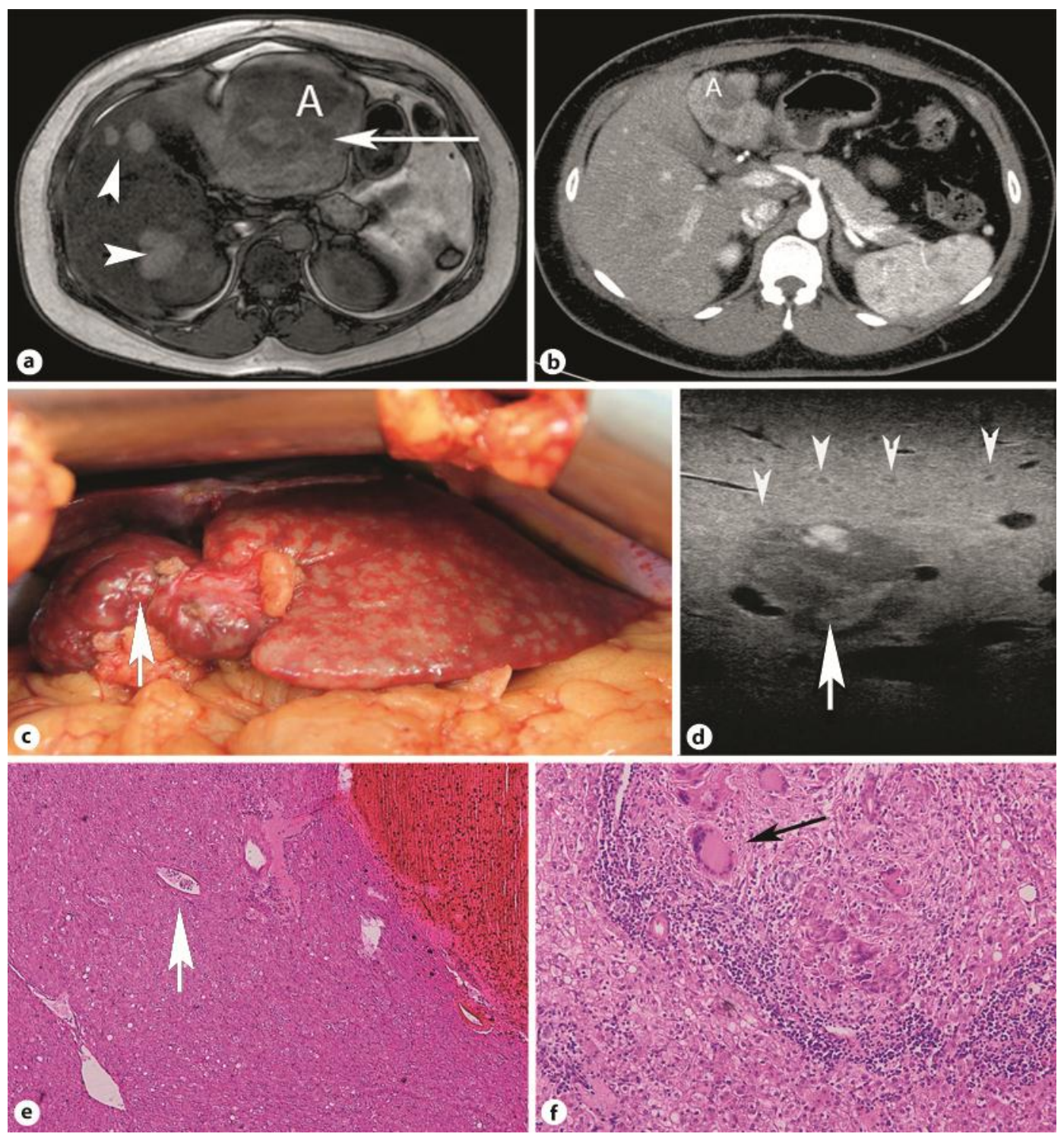

Fig. 1. Case 1: imaging and histopathology. a MR image of a 36-year-old woman who presented with acute abdominal pain. The transverse T1-weighted fat-suppressed image shows a lesion in the left liver (A) with hypodense areas consistent with bleeding (arrow). Furthermore, multiple hyperintense lesions compared to the surrounding liver parenchyma are shown (arrowheads). b CT image of the same patient 1 year after the bleeding when she presented with recurrent upper abdominal pain. The transverse image of the arterial phase shows the shrunken lesion in the left liver (A), with a new hypodense area consistent with recent bleeding. Based on the symptoms of upper abdominal pain and the signs of bleeding on imaging, the patient was advised to undergo resection of the lesion. c Macroscopic appearance of the liver at laparotomy, revealing an inhomogeneous liver surface, disseminated pale lesions of approximately $1.0 \mathrm{~cm}$ with a tendency to confluence, and a large well-circumscribed lesion in the left liver lobe (arrow). $\mathbf{d}$ Intraoperative ultrasound shows the HCA lesion (arrow) and multiple, atypical, small hypodense lesions throughout the liver (arrowheads). e Microscopic appearance of the resected HCA in the left liver lobe. This specimen shows the benign hepatocellular proliferation growing in sheets of cords, without pseudoglandular growth patterns. Solitary arteries (arrow) are seen and portal tracks are lacking (hematoxylin-eosin, 4×). f Microscopic appearance of the surrounding liver parenchyma with a granuloma containing multinucleated giant cells (arrow) (hematoxylin-eosin, 10x). 

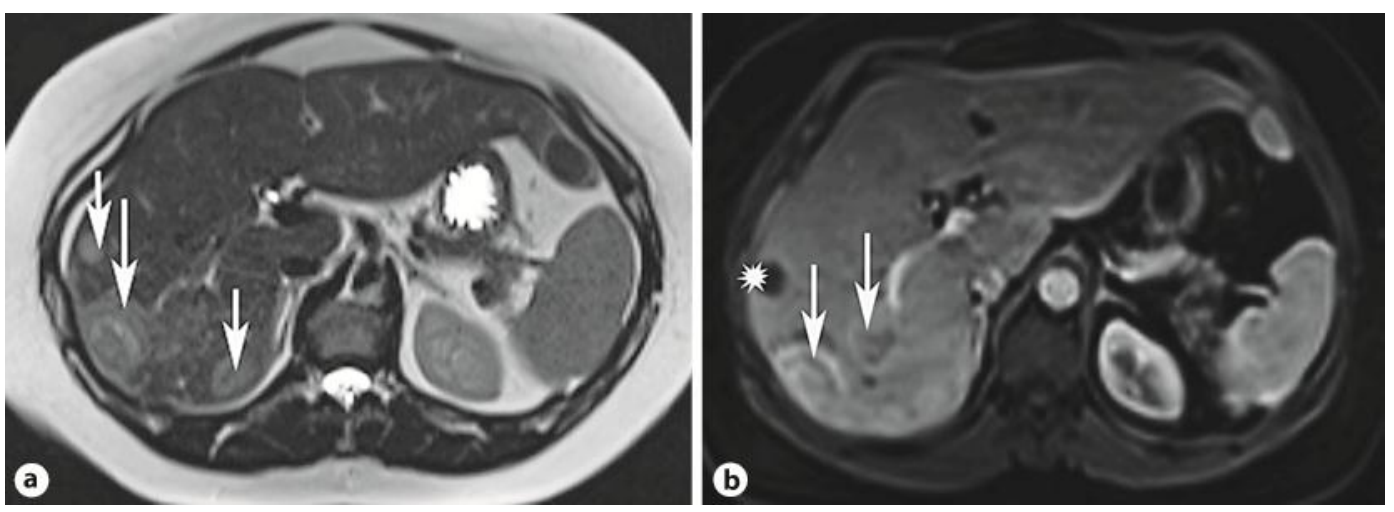

Fig. 2. Case 2: MR imaging. a The transverse T2-weighted MR image of the 29-year-old patient shows multiple slightly hyperintense lesions throughout the liver (arrows). b Early enhancement of the lesion on T1-weighted arterial phase of MR imaging is seen. The ill-defined lesion in the right liver shows hypodense areas consistent with recent bleeding (arrows). ${ }^{*}$ Simple liver cyst.

\section{References}

1 Bioulac-Sage P, Laumonier H, Couchy G, et al: Hepatocellular adenoma management and phenotypic classification: the Bordeaux experience. Hepatology 2009;50:481-489.

2 Bioulac-Sage P, Blanc JF, Rebouissou S, Balabaud C, Zucman-Rossi J: Genotype phenotype classification of hepatocellular adenoma. World J Gastroenterol 2007;13:2649-2654.

-3 Mir-Madjlessi SH, Farmer RG, Hawk WA: Granulomatous hepatitis. A review of 50 cases. Am J Gastroenterol 1973;60:122-134.

4 Lagana SM, Moreira RK, Lefkowitch JH: Hepatic granulomas: pathogenesis and differential diagnosis. Clin Liver Dis 2010;14:605-617.

-5 Le Bail B, Jouhanole H, Deugnier Y, et al: Liver adenomatosis with granulomas in two patients on long-term oral contraceptives. Am J Surg Pathol 1992;16:982-987.

6 Grazi GL, Vetrone G, Ercolani G, et al: Associated benign liver tumors in idiopathic granulomatous hepatitis: a case report. Hepatol Res 2007;37:568-571.

-7 Martin-Blondel G, Camara B, Selves J, et al: Etiology and outcome of liver granulomatosis: a retrospective study of 21 cases. Rev Med Interne 2010;31:97-106.

8 Bioulac-Sage P, Balabaud C, Zucman-Rossi J: Subtype classification of hepatocellular adenoma. Dig Surg 2010;27:39-45.

-9 van Aalten SM, Verheij J, Terkivatan T, Dwarkasing RS, de Man RA, Ijzermans JN: Validation of a liver adenoma classification system in a tertiary referral centre: implications for clinical practice. J Hepatol 2011;55:120-125.

10 Malatjalian DA, Graham CH: Liver adenoma with granulomas. The appearance of granulomas in oral contraceptive-related hepatocellular adenoma and in the surrounding nontumorous liver. Arch Pathol Lab Med 1982;106:244-246.

11 Kleiner DE: Granulomas in the liver. Semin Diagn Pathol 2006;23:161-169.

12 Abt AB, Kirschner RH, Belliveau RE, et al: Hepatic pathology associated with Hodgkin's disease. Cancer 1974;33:1564-1571.

13 Ishak KG: Hepatic neoplasms associated with contraceptive and anabolic steroids. Recent Results Cancer Res 1979;66:73-128.

14 Rooks JB, Ory HW, Ishak KG, et al: Epidemiology of hepatocellular adenoma. The role of oral contraceptive use. JAMA 1979;242:644-648.

15 Neuberger J, Portmann B, Nunnerley HB, Laws JW, Davis M, Williams R: Oral-contraceptive-associated liver tumours: occurrence of malignancy and difficulties in diagnosis. Lancet 1980;1:273-276. 